Aus dem Pathologischen Museum der Charité in Berlin. (Leiter: Geheimrat Orth.)

\section{Ueber die künstliche Weiterentwicklung (in vitro) des Tertian-Malariaparasiten.}

\author{
Von Prof. H. Ziemann in Charlottenburg.
}

Die frïheren Versuche der Malariaforscher, die Malariaparasiten im Blut kïnstlich weiter zu kultivieren, sind stets negativ verlaufen. Ich selber habe Malariaparasiten frïher in Blutegeln, die ich Malariapatienten angesetzt hatte, zu konservieren versucht, den Kern färberisch nach meiner Romanowsky-Methodo auch tagelang noch weiter nachweisen, eine Vermehrung aber nicht erzielen können. $\left.{ }^{1}\right)$ Da veröffentlichten Bass und Johns, Oktober 1912², die Technik der erfolgreichen Kultivierung des Tertian- und Perniciosaparasiten.

Die springenden Punkte der betreffenden Technik sind, abgesehen von selbstverständlich strengster Asepsis, 1. Beimengung von Dextrose in bestimmter Menge zu dem Malariablut, 2. möglichster Sclıutz der malariainfizierten roten Blutkörperchen gegen die Einwirkung der Luft, 3. Aufbewahren der Kulturröhrchen bei $40^{\circ} \mathrm{im}$ Brutschrank, 4. Entfernung der Leukozyten aus dem Malariablut bei Anlegen von Tochterkulturen, indem man durch nicht zu starkes und nicht zu lange fortgesetztes Zentrifugieren die weißen Blutkörperchen aus der Tiefe allnählich in die Höhe treibt, worauf man sie abpipettieren kann. Die Parasiten können dann in den roten Blutkörperchen unter der schützenden, darüber stehenden, mindestens $2,5 \mathrm{~cm}$ hohen Serumschicht wiederum sporulieren.

Die mir von Bass am 25. September 1912 zur Begutachtung ïbersandten Präparate von künstlich weitergezüchteten Perniciosaparasiten gaben mir schon damals die Ueberzeugung, da $B$ er in der Tat das hochwichtige und interessante Problem gelöst hatte. Es fanden sich speziell in dem Präparat von einer 60 Stunden alten Perniciosakultur ïberalterte Formen, die im peripherischen Blute niemals beobachtet werden. Bekanntlich beträgt ja die natïrliche Entwicklıngsdauer des Perniciosaparasiten in maximo auch nur 48 Stunden.

Außerdem konnte man in den $30-40$ Stunden alten Kulturpräparaten die ganze Entwickling des Perniciosaparasiten verfolgen, was im peripherischen Blute bekanntlich nicht oder selten möglich ist. Ueber meine an Hand der übersandten Präparate gemachten Wahrnehmungen cfr. $^{3}$ )

Meine sofort eingeleiteten Bemühungen, Fälle von Perniciosa mit reichlichem Parasitenbefunde behufs Nachprüfung zu bekommen, waren leider gerade in dieser Zeit negativ. Fast alle meine Patienten hatten vorher Chinin genommen, sodalo der Parasitenbefund derselben 0 bzw. nur festzustellen war bei Anwendung der sogenannten Methode des dicken Tropfens. Die Kulturversuche in einem solchen Falle mit äußerst spärlichem Parasitenbefund verliefen negativ.

Da stellte ich am 15. Januar, $7 \mathrm{pm}$ bei einem ambulant behandelten Patienten G., (zur Jagd in Ostafrika gewesen) ein Tertianarezidiv fest. In den Präparaten einige spärliche geschlechtliche und ungeschlechtliche Parasiten von meist $2 / 3$ bis $3 / 4$ Größe eines roten Blutkörperchens und darüber. Schon in der Nacht zum 16. Jannar starker Fieberanfall. Akme 2 Uhr nachts. Am 16. Januar. 91/, Uhr noch Schweißausbruch, Temperatur 37,7. Im peripherischen Blute jetzt schon endoglobuläre, noch ringförmige Parasiten. Einige geschlechtliche, endoglobuläre größere Formen mit lebhaft beweglichem Pigment, wenige pigmenthaltige Leukozyten. Blutentnahme behufs Kultur. Hierauf aufrechtes Einstellen in den Brutschrank bei 39,5 . Bei dem Patienten war die Temperatır nie über 39,5 hinausgegangen. Die Entnahme des Blutes und der Transport per Auto bis zum Laboratorium dauerte etwa $40 \mathrm{Mi}$ nuten. Medikation: Chininum tannicum, 2 mal täglich 0,5. Am Rest des 16. Januar weiter Wohlbefinden, Apyrexie. Die Parasiten, entnommen aus. der Schicht dicht unter der Oberfläche der BlutkörperchenSedimentschicht, waren am 16. Jannar $3 \mathrm{pm}$ in den Kulturen etwas gewachsen, noch mehr um 6 Uhr nachmittags. Am 17. Januar. $10 \mathrm{Uhr}$ morgens Parasitenbefund in den Kulturen negativ, starkes Bakterienwachstum. Dieser Versuch konnte daher nicht als beweisend gelten. Am 17. Janiar vormittags 10 am T. 36. Im Blute des Patienten cinige halb, meist zu Zweidrittel erwachsene Parasiten und einige, scheinbar durch das am 16. Januar gegebene Chinin schon beeinflußte Fornien. $6 \mathrm{Uhr}$ nachmittagsTemperatur 37,2. $\mathrm{lg}$ Chin. hydrochlor. auf einmal. Vorher Punktion einer Vene. Sterile Entnahme von etwa $80 \mathrm{ccm}$ Blut für Kultır-

I) Ueber Malaria und andere Blitparasiten nebst Anhang. Eine wirksame Methode der Chromatin- und Blutfärbung. 1898. - 2) Journal of experiment. Medic. Oct. 1912. $-{ }^{3}$ ) Zentralblatt für Bakteriologie, Bd. 67, H. 6 . versuche, da in der Nacht bzw. gegen Morgen noch Fieberanfall zu erwarten war. In dem peripherischen Blute $3 / 4$ bis erwachsene Parasitell. ${ }^{1}$ ) Chromatinteilung erst im allerersten Stadium. Befund also fast genau wie am 15. Januar $7 \mathrm{Uhh}^{\circ}$ nachmittags, zweì Tage vorher. In der Nacht Fieberanfall. Ein Teil des cntnommenen defibrinierten Blutes wurdc zur Kontrolle ohne Dextrosezusatz gelassen. Es sei vorweg bc. merkt, daß es bei sonst gleicher Technik in diesem Blute nicht zur Sporulation der Parasiten kam. Der Rest des Blites wurde $111 \mathrm{it} 50 \%$ iger Dextrose versetzt, und zwar zum Teil 8, 10, 12 ccul Blut mit je ${ }^{1} / 10 \mathrm{ccm} 50 \%$ iger Dextroselc̈sung. Das Verhältnis von ${ }^{1} /{ }_{10} \mathrm{cen}$ । $50 \%$ iger Dextroselösıng: $8 \mathrm{ccm}$ Blut schien mir später die günstigstc zu sein (nach Bass 1 : 10). Zeitdauer von Entnahme des Blutes bis zum Einstellen in den Brutschrank 39,50 $\mathrm{C}$ etwa 40 Minnten: Dort, wo das Serum nicht cine inindestens $2,5 \mathrm{~cm}$ hohe Flüssigkeitssäule abgab, fügte ich bei $45^{\circ} \mathrm{C}$ eine Stunde inaktiviertes steriles Ascites-Serum zil. Es sei gleich bemerkt, daß gegenüber dem Blutserum kein Unterschied zu kon s.tatieren war. In allen Röhrchen ging während der Nacht dic Sporulation der Parasiten vor sich. Leider konnte wegen Schluß des Muscums während der Nacht die Entwicklung nicht häufiger kontrolliert werden.

Am 18. Januar, 10 Uhr morgens, zu einer Zeit, als Patient im Schweißstadium noch $38,6^{\circ}$ zeigt, in der dicht unter der Oberfläche der Blutkörpersedimentschicht befindlichen Kulturlage a) einige Formen mit 8-10 Kernen (Nachzügler in der Sporulation), b) eine mäßige Anzahl junger endoglobulärer ringförmiger Parasitcu, einigo ev. durch Chinin beeinflußt (die von ihnen infizierten roten Blut. körpcr mit dentlicher Schüffner-Tüpfelung), c) eine große Menge ausgebildeter Sporulationskörper, die nur im gefärbten Präparat als abgestorben zll bezeichnen waren, indeln das Chromatin der Merozoiten staubförmige Auflösung zeigte und das Plasma keine Färbung mehr annahm, d) eine große Menge pigmenthaltiger Leukozyten, wie man sic im peripherischen Tertiana-Blut niemals in solcher Menge sieht. Die $\mathrm{Ph}$ agozytose zeigtc sich bei allen Leukozyten, nicht nur bei den großen einkernigen. Der Befund ad $a-b$ und d entsprach in der Kultur also ganz dem im Fieberabfall im peripherischen Blute üblichen.

Am 18. Januar 4 Uhr pnl. in der Kultur reife, lebende Sporılationsformen verschwunden, einige größere endoglobuläre junge Tertianaparasiten, sehr wenige männliche halb und ganz erwachsene, geschlechtliche (!) Parasiten mit lebhaft beweglichem Pigment. Da die Leukozyten garnicht entfernt waren, mußte die Mehrzahl der freigewordenen Merozoiten phagozytiert werden. Sonst Befund wie am 18. Januar. Patient fieberfrei. Von jetzt an drei Tage 4 mal täglich 0.5 Chinin. tannic. Parasiten im Patienten nicht mehr nachweisbar. 19. Januar. $10 \mathrm{Uhr}$ morgens, in der Kultur jüngste endoglobuläre ungeschlechtliche Parasiten. Nach langem Suchen noch ein erwachsener Parasit und zwei geschlechtliche mit beweglichem Pigment. Sehr viel pigmenthaltige Lenkozyten. Im peripherischen Blute des Patienten nur noch Mononukleose. Am 20. Januar 1 pm. in Kultur 1 Eyp. inännlich und weiblich. Größerer Parait. Pignenthaltige Leukozyten.

Es hatte also, wenn man den Befund des peripherischen Blutes am 17 . Januar 6 Uhr nachmittags mit dem der Kultur vom 18. Januar 10 Uhr vornittags, 4 Uhr nachmittags etc. vergleicht, eine unzweifelhafte Weiterentwicklung stattgefunden. Charakteristischerweise hatten die geschlechtlichen, als besonders resistent schon früher bekannten Formen sich länger behauptet als die ungeschlechtlichen.

Der Grund dafür, daß stärkere Weiterentwicklıng noch nicht in mehrfacher Generation gelang, wird gelegen haben in der vorhergegangenen Chinisierung des Patienten, der relativ langen Abkühlung des Malariablutes während des Transportes und darin, daß zur Zeit des Versuchs für die Kultivierung mehrfacher Generationen nur Blut, das bereits 24 Stunden im Kühlschrank gestanden, zur Verfügung war. Außerdem macht Bass selbst auf die Schwierigkeit der Kultur gerade des Tertianparasiten aufmerksam. Die Dextrose, deren Bedeutung bei der Kultur Bass im Unklaren läßt, hat meines Erachtens auch die Aufgabe, rein nechanisch die Oberfläche der roten Blutkörper klebriger zu machen, soda $\beta$ die Merozoiten leichter festkleben und in die roten Blutkörperchen eindringen können. Ueber die große Bedeutung der Bassschen Entdeckung mehr in der ausführlichen Mitteilung. Herrn Geheimrat Orth sage ich für die Ueberlassung eines Laboratoriumraumes herzlichen Dank.

1) Junge, ringförmige Parasiten waren nirgends zll schen, wohl aber $16 \mathrm{~h}$ später im Kulturblut. 